\title{
Effect of Frost on Triticale and Wheat Varieties at Flowering in the North Eastern Australian Cereal Belt
}

\author{
S. TSHEWANG ${ }^{1,2 *}$, R. JeSSOP ${ }^{1}$ and C. BirChALL ${ }^{1}$ \\ ${ }^{1}$ School of Environmental and Rural Science, University of New England, Armidale, NSW 2351, Australia \\ 2Present address: Agriculture Research and Development Sub Center, Department of Agriculture, \\ Ministry of Agriculture and Forests, Tsirang, Bhutan
}

(Received 16 November 2016; Accepted 5 May 2017;

Communicated by L. Bona)

\begin{abstract}
Spring radiation frost is a serious problem in Australia particularly at the reproductive stage, causing an annual revenue loss of more than AU\$ 360 million. The focus of frost research therefore has been to identify reproductively frost resistant cereals at the both varietal and species levels that can contribute to alleviating frost damage. Seven triticale and three wheat varieties were assessed to determine relative frost tolerance under natural frost conditions. Plants were grown in pots and raised in the glasshouse. At flowering ( \pm 5 days), plants were exposed to a single overnight frost or frost maintained for a short time with varying intensities from 0.2 to $-6.6{ }^{\circ} \mathrm{C}$ at crop ear height. The frost impact was assessed at maturity based on ear fertility by counting the number of developed grains. There were variable levels of tolerance between triticale varieties with Tahara being more susceptible than other varieties. At species level, triticale was more susceptible than wheat. Temperatures below $-3.9^{\circ} \mathrm{C}$ were economically damaging. A holistic approach of breeding and agronomic management may be needed to mitigate the frost problem in winter cereals.
\end{abstract}

Keywords: frost resistance, fertility, triticale

\section{Introduction}

The growth of winter cereals throughout the globe is affected by a number of abiotic stresses, temperature extremes being among them. Of particular importance is low temperature caused by spring radiation frosts, which occur when the night temperatures fall below zero under the conditions of clear skies, calm cold air, dry atmospheric conditions and temperature inversions (Snyder and de Melo-Abreu 2005). Ear frosting is a significant problem in all grain growing regions of Australia (Boer et al. 1993; Frederiks et al. 2011). The national revenue loss due to frost in Australia is estimated about AU\$ 360 million annually (Grains Research Development Corporation 2013) though the amount varies widely between years.

Winter cereal crops such as wheat and triticale are susceptible to frost throughout the entire growing period from vegetative to reproductive stages. Crops generally exhibit a higher degree of cold tolerance at vegetative stages, even down to $-20^{\circ} \mathrm{C}$, but such levels 
are not exhibited at reproductive stages (Fuller et al. 2007). Most economic damage though is through reduced grain yield and quality degradation caused when frosting occurs between the booting and grain ripening stages (Single and Marcellos 1974; Rebbeck et al. 2007). Even among these stages, flowering is the most sensitive stage where the reproductive parts are not protected by the leaf sheath (Marcellos and Single 1984; Cromey et al. 1998) and ice nucleates directly on reproductive parts (Single and Marcellos 1974). Ice nucleation is detrimental in affecting fertilization and grain formation, resulting in complete sterility and/or shriveled grains associated with ear whitening. Frost also has a negative effect on grain quality (Allen et al. 2001).

Understanding the relative frost tolerance responses of different winter cereals at both the species and varietal levels is important from breeding and farming perspectives. Different screening methods for frost evaluation have been developed and suggested (Frederiks et al. 2012). However, few varieties with definite genetic advantages have been identified. Frederiks et al. (2011) reported that the barley (Hordeum vulgare L.) varieties Gilbert and Kaputar, which demonstrated resistance in northern Australia were not exhibiting the same in southern region of Australia. In part, this was because assessment is constrained by differences in crop phenology, canopy development, experimental methods and genotype $\times$ environment interaction. However, even a broader classification of species tolerance is uncertain, with Synder and de Melo-Abreu (2005) reporting that frost resistance among species was in the order rye (Secale cereale L.) $>$ bread wheat (Triticum aestivum L.) $>$ triticale $(\times$ Triticosecale Wittmack $)>$ barley $>$ oats $($ Avena sativa $\mathrm{L}$.$) and$ durum wheat (Triticum durum Desf.), whereas Rebbeck et al. (2007) reported that triticale was the most susceptible crop followed by wheat, barley, rye and oats. Limin and Fowler (1991) also reported that triticale was no better than wheat in cold hardiness as its expression of cold-hardiness genes transferred from rye was suppressed by the wheat genome.

Many ear frost studies have been conducted in wheat in Australia since the mid-1900s (e.g., Single and Marcellos 1974; Marcellos and Single 1984), indicating the significance of frost damage on wheat to the local agriculture and economy. However, studies have been extended more recently to other winter cereals such as barley (Reinheimer et al. 2004; Frederiks et al. 2011). Despite frost being a recurrent problem for triticale production and expansion in Australia (Roake et al. 2009), no similar studies have been undertaken on this crop. The aim of this study was to assess the relative frost responses of triticale varieties following natural frost events, and how triticale performs compared with bread wheat.

\section{Materials and Methods}

\section{Plant materials}

Seven varieties of triticale (Bogong, Tahara, H20, H151, Canobolas, H426, and JRCT 400) were tested in 2009. In 2010, four varieties (Tahara, H20, H426 and JRCT 400) were further evaluated. Triticale genotypes were spring type released varieties or advanced 
generation breeding lines. In both years Tahara was used as a standard for varietal comparisons as it was still grown commercially in some locations. In 2010, three varieties of spring type bread wheat (Young, Kite, and Wyalkatchem) were tested to assess the species difference between wheat and triticale. The seeds of these varieties were sourced either from the University of New England or Plant Breeding Institute, The University of Sydney or Department of Agriculture and Food, Western Australia.

\section{Plant growth}

In both years, three seeds of each variety to be tested were sown in pots $(7.5 \times 7.5 \times 20 \mathrm{~cm}$ deep) containing a grey vertosol at $\mathrm{pH} 5.2$ and organic matter content of $2.35 \%$. One week after emergence, plants were thinned to one healthy plant per pot. Twelve pots of each variety were sown weekly over a five-week period to generate a wide spread of flowering times that facilitated selection and treatment of different varieties at the same developmental stage (flowering). Crop fertilization, plant protection and other agronomic measures were provided as necessary to obtain healthy plants. Plants were placed randomly in a glasshouse compartment both before and after frost treatments. Plants were irrigated prior to frosting as frost damage is worse in dry soils, possibly due to greater injury to roots (Chen et al. 1983).

Plants were raised in a naturally lit glasshouse at the University of New England, Armidale (1,000 masl) with temperatures of $20 / 10^{\circ} \mathrm{C}$ (day/night). It is common in Armidale to experience subzero temperatures during the June to August winter months. Tillers were tagged when at emergence of the top spikelet on each ear, and the number of days to anthesis was monitored for each variety. Anthesis generally occurred 14 days after spikelet emergence for triticale and 10 days for wheat. For frost treatments, only main tillers within \pm 5 days of flowering were selected. In this way, the confounding effect of frost escape from early or late flowering during the frost event was minimized.

\section{Frost treatments}

In 2009, frost treatments were imposed when sufficient plants within \pm 5 days of anthesis were available, and when temperatures were forecast to fall below $0{ }^{\circ} \mathrm{C}$ overnight according to the Bureau of Meteorology website. Selected plants were taken to an open paddock at $5 \mathrm{pm}$ and spaced approximately $40 \mathrm{~cm}$ apart to allow free air flow and to avoid the influence of a thick crop canopy. The pots were buried to prevent freezing of the roots, and plants with weak stems loosely tied to bamboo stakes to prevent lodging. Four Thermocron iButton DS1922L temperature loggers tied to bamboo stakes were placed at plant ear height, with the minimum temperature for the night being averaged to determine floret exposure temperature. After an overnight exposure, plants were returned to the glasshouse at around 9 am and grown to maturity.

In 2010, frost treatments were modified according to the lessons learnt in the 2009 experiment. Given the unpredictable and uncontrollable nature of natural frosts, many plants were completely damaged in 2009 , when there was a heavier frost than forecast. 
Therefore, to avoid such fatality and to treat the plants at a wide range of temperatures, the technique was modified whereby the available plants were exposed to the frost then rescued once the desired temperature was attained. In this way, severe damage was avoided and frost temperatures were maintained for short periods only. These expectations, however, were not fully achieved as there were three nights $\left(-3.5,-2.8\right.$ and $\left.-2{ }^{\circ} \mathrm{C}\right)$ where temperatures did not go lower despite monitoring for the whole night. Therefore, the modified method was applied to two treatments $\left(-4.5\right.$ and $\left.-3.9^{\circ} \mathrm{C}\right)$ only.

In 2010, plants were selected and placed in the open space in a similar way to 2009. To prevent freezing of roots and soil, pots were placed in larger pots and surfaces were covered with potting mix. As plant height could have a confounding effect, plant height was equalized by elevating the ears of all plants to the same height. Four Thermocron iButton DS1922L temperature loggers were placed at ear height to record the temperatures. The frost temperatures were monitored frequently by reading two data loggers alternatively. After the attainment of desired temperatures, plants were transferred to a cool room with a temperature of $4.5^{\circ} \mathrm{C}$ to avoid fast thawing. Plants were transferred to the glasshouse the following day at 9 am and grown to maturity as in 2009 .

\section{Data collection and statistical analysis}

Frost damage at maturity was assessed in terms of ear fertility by counting the number of grains set per ear, similar to measurements by other workers (Marcellos and Single 1984; Maes et al. 2001). An individual tagged and frosted ear was considered as a single replicate, and varieties without a minimum of 3 plants for a single frost event were not included in data analysis. Proportion of grain set per ear was recorded by dividing the number of fertile florets by the total number of potential viable florets. Data were analyzed by data analysis software R (R Development Core Team 2010) using a generalized linear model with quasibinomial distribution. Main effects were considered to be temperature and genotypes and each plant was considered a random replicate. Significant difference was calculated at the $P<0.05$ probability level. The differences between means were separated by $95 \%$ confidence interval. It is a conservative comparison method, which provides information on both location and precision that can be used to make a significance decision (Payton et al. 2003).

\section{Results}

\section{Frost events}

The available plants were exposed to one of six frost events between June and August in both years. In 2009, temperatures were measured at $-6.6,-4.2,-3.5,-1.9,-1.7$ and $0.2{ }^{\circ} \mathrm{C}$, and measured temperatures in 2010 were $-6.5,-4.5,-3.9,-3.5,-2$ and $-1.5^{\circ} \mathrm{C}$. The minimum temperature measured in the glasshouse for the control treatment was $8{ }^{\circ} \mathrm{C}$ in both years. As envisaged, the forecast of minimum temperatures by the meteorology station and actual temperature measured at the site during the frost events differed. 

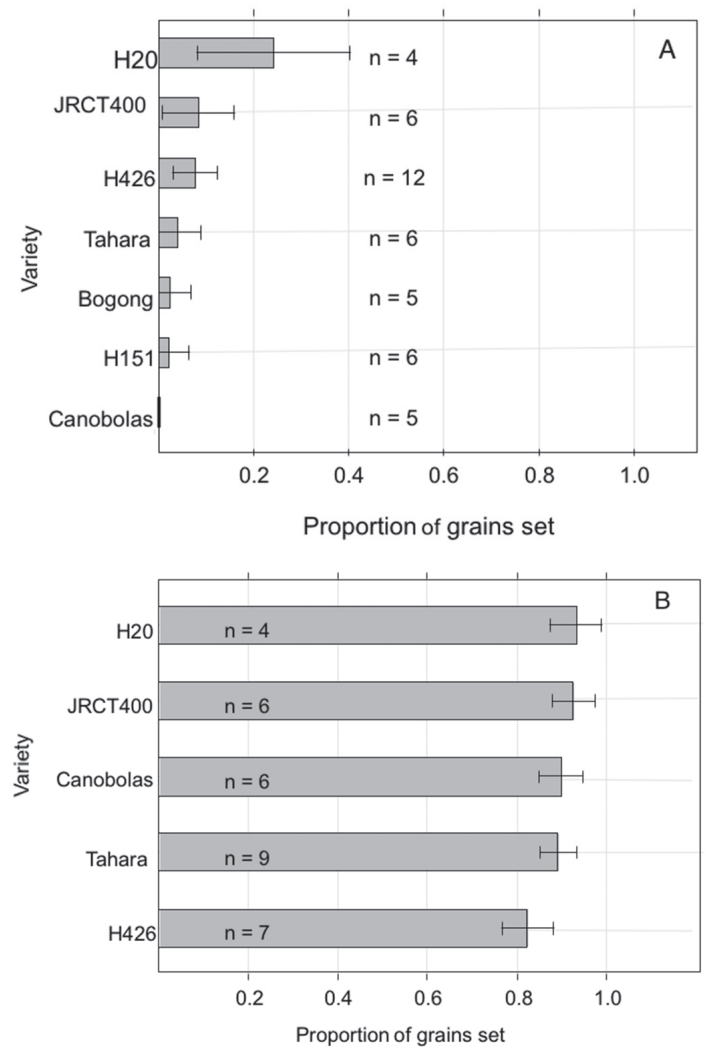

Figure 1. Proportion of grain set in different triticale varieties in 2009. "n" is the number of ears frosted. Bars are the $95 \%$ confidence interval calculated for a binomial distribution. (A) $-4.2^{\circ} \mathrm{C}$ frost at plant ear height on 17 July. (B) $-3.5^{\circ} \mathrm{C}$ frost at plant ear height on 19 July

Frost temperatures of 0 to $-2{ }^{\circ} \mathrm{C}$ at ear height did not cause significant damage, and the proportions of grains set were comparable to those of untreated plants, being above $95 \%$ in both years. The grain set in all the untreated varieties in both years was above $95 \%$. Conversely, severe frosts with a minimum temperature of $-6.5^{\circ} \mathrm{C}$ and below caused severe damage to both ears and plant shoots leading to complete sterility. Even a short period of exposure to temperatures around $-6.5^{\circ} \mathrm{C}$ was lethal to all tested varieties.

\section{Frost tolerance of triticale varieties (2009)}

With no considerable damage to florets by a milder frost event of $-2{ }^{\circ} \mathrm{C}$ and above, and complete sterility at $-6.5^{\circ} \mathrm{C}$ and below in both years, suitable data were gathered from only four frost events $\left(-4.5,-4.2,-3.9\right.$ and $\left.-3.5^{\circ} \mathrm{C}\right)$. Obvious differences in the degree of damage were observed within the triticale varieties exposed to $-3.5^{\circ}$ to $-4.5^{\circ} \mathrm{C}$. In 2009 , 

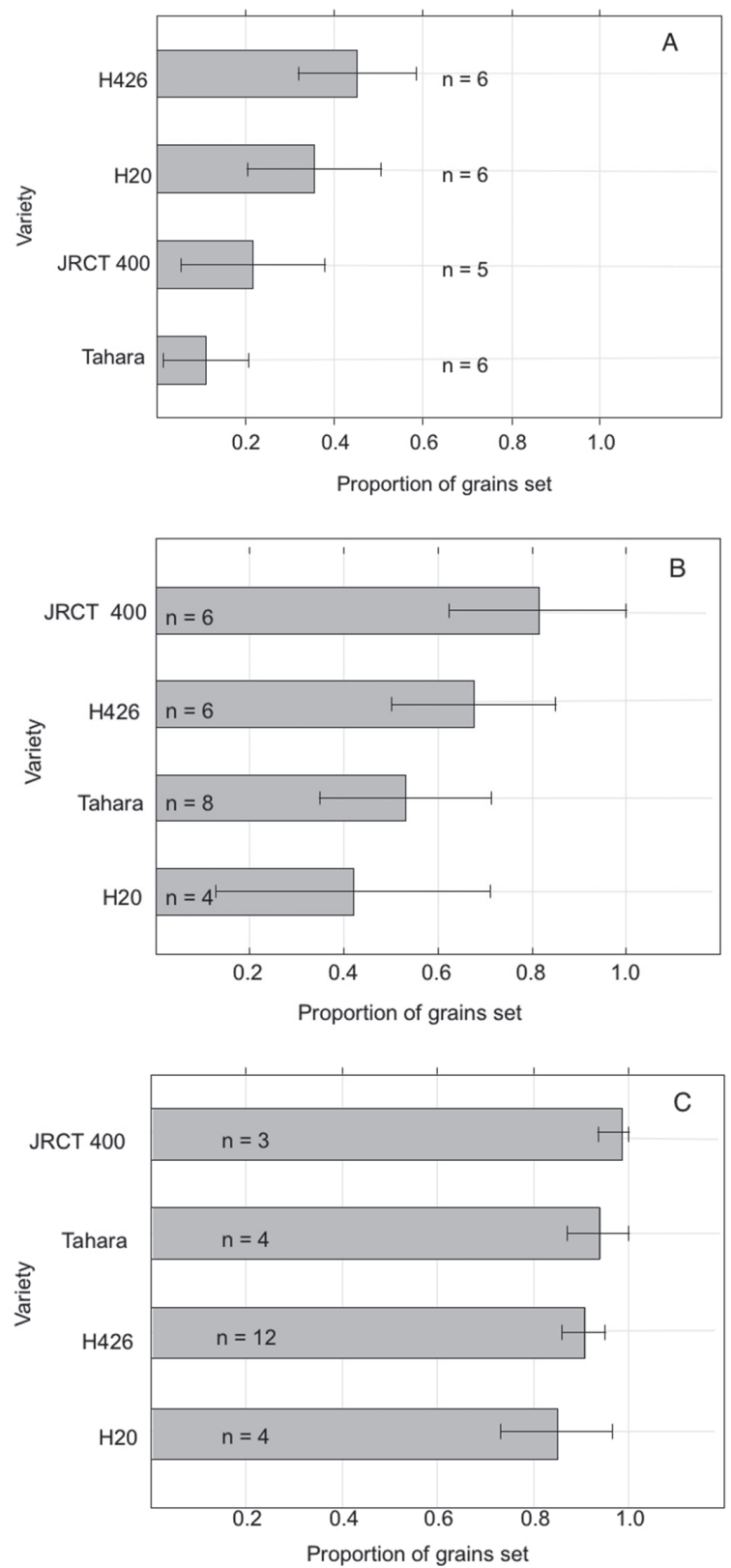

Figure 2. Proportion of grain set in different triticale varieties in 2010. " $\mathrm{n}$ " is the number of ears frosted. Bars are the $95 \%$ confidence interval calculated for a binomial distribution. (A) $-4.5^{\circ} \mathrm{C}$ frost at plant ear height on 29 June. (B) $-3.9^{\circ} \mathrm{C}$ frost at plant ear height on 17 July. (C) $-3.5^{\circ} \mathrm{C}$ frost at plant ear height on 30 June 
there was a significant influence of temperature $-4.2{ }^{\circ} \mathrm{C}$ on grain set, and triticale varieties differed significantly $(P<0.05)$ (Fig. 1A). A frost of $-3.5^{\circ} \mathrm{C}$ had a significant effect, but triticale varieties did not differ with respect to grain set (Fig. 1B). In both the cases, H20 and JRCT 400 had the highest floret survival suggesting that they may be more tolerant than the other varieties. Unfortunately, Bogong and H151 could not be evaluated at $-3.5^{\circ} \mathrm{C}$ as no plants at anthesis were available.
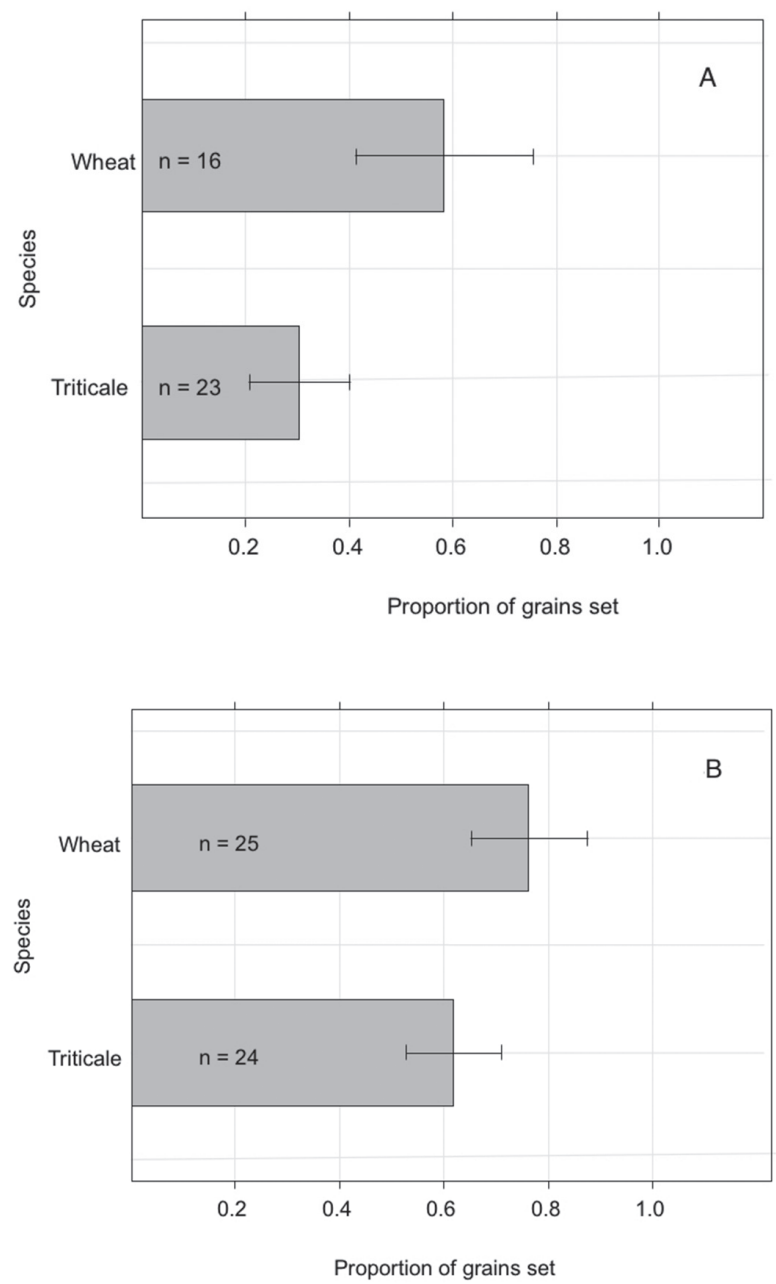

Figure 3. Proportion of grain set in different species in 2010. " $n$ " is the number of ears frosted. Bars are the $95 \%$ confidence interval calculated for a binomial distribution. (A) $-4.5^{\circ} \mathrm{C}$ frost at plant ear height on 29 June. (B) $-3.9^{\circ} \mathrm{C}$ frost at plant ear height on 17 July 


\section{Frost tolerance of triticale varieties (2010)}

At $-4.5^{\circ} \mathrm{C}$ frost, there was a significant effect of both temperature and varieties on floret fertility $(P<0.05)$ (Fig. 2A). Frosts of $-3.9^{\circ} \mathrm{C}$ and $-3.5^{\circ} \mathrm{C}$ also had significant effects on ear fertility but there was no difference between triticale varieties as in Fig. $2 \mathrm{~B}$ and Fig. 2C, respectively. While relative ranking changed slightly between the years, variety Tahara performed worst in both years, particularly below $-4.2^{\circ} \mathrm{C}$.

\section{Species tolerance (2010)}

Statistical analysis showed a significant effect of both $-4.5^{\circ} \mathrm{C}$ frost temperature and species $(P<0.05)$ on floret survival. Triticale was more damaged than wheat, with the grain set in wheat being almost twice that of triticale at this frost (Fig. 3A). Grain setting in the two species was found to be significantly reduced by a frost temperature of $-3.9{ }^{\circ} \mathrm{C}$ $(P<0.05)$, though the two species did not differ statistically $(P>0.05)$ (Fig. 3B). There was a suggestion that wheat continued to set more grain than triticale. The grain set in both triticale and wheat at $-3.9^{\circ} \mathrm{C}$ was higher than the frost of $-4.5^{\circ} \mathrm{C}$.

\section{Discussion}

The search for winter cereal varieties with good ear fertility despite frosting at the reproductive stage continues to be a priority research outcome in Australia. Frosts at the reproductive stage cause the most extensive damage by nucleation of ice in the floral parts, thereby affecting grain development (Single and Marcellos 1974; Cromey et al. 1998). Winter cereals with frost tolerance would have a great positive impact on cereal production in Australia (Frederiks et al. 2015), and a yield benefit of up to $20 \%$ could be realized (Zheng et al. 2015). The work presented here suggests that there may be minor varietal differences in frost tolerance as the tested triticale varieties differ in ear fertility, particularly at frost temperatures below $-3.9^{\circ} \mathrm{C}$.

There were changes in the relative ranking of ear fertility between triticale varieties across years at frost temperatures especially below $-3.9{ }^{\circ} \mathrm{C}$. This was not unexpected as frost researchers have reported year to year variation in varietal ranking (Frederiks et al. 2011). The contributing factors to these alterations are not understood, but it is likely that differences in experimental methods used were contributing factors to the variation in outcome. In 2009, the plants were kept in the field overnight while the treatment in 2010 was only until a particular temperature was reached, followed by plant rescue. The duration of frosting has adverse effects with more damage resulting from prolonged treatment (Cromey et al. 1998). The data from a $-4.2^{\circ} \mathrm{C}$ frost in 2009 and $-4.5^{\circ} \mathrm{C}$ in 2010 support this possibility, with more damage occurring in 2009 even though the temperature was higher. Collectively, the data indicate that triticale variety, Tahara may not be the best option in frost-prone areas that experience frost temperatures of less than $-3.9^{\circ} \mathrm{C}$ as this variety suffered the most damage in both years.

The nomination of a critical temperature at either species or variety level has been a challenge given inconsistent results from both controlled and field frost experiments. 
Thus, a temperature range of -3 to $-5^{\circ} \mathrm{C}$ has generally been considered as the lethal temperature for winter cereals, especially at the time of flowering (Single and Marcellos 1974). However, the degree of injury is highly sensitive to temperature and there can be severe damage even to complete ear sterility when the temperature drops $1{ }^{\circ} \mathrm{C}$ below its threshold (Marcellos and Single 1984). The current study noted that temperatures below $-3.9^{\circ} \mathrm{C}$ could be lethal for winter cereals, particularly triticale, as there was substantial reduction in grain set. Single and Marcellos (1974) also documented $-3.9^{\circ} \mathrm{C}$ as a critical temperature for frost damage in winter cereals at flowering. Damage from temperatures of $-3.9^{\circ} \mathrm{C}$ and below are likely due to ice nucleation, with Hacker et al. (2010) reporting initiation of ice nucleation around $-4{ }^{\circ} \mathrm{C}$ during frost. Some damage could also be expected from other frost temperatures such as $-3.5^{\circ} \mathrm{C}$, but the yield loss might not be sufficiently severe to have considerable impact.

Frost studies have been constrained by many confounding factors. The chamber studies which can monitor and control the temperatures, are unsuitable for screening in-head frost resistance (Frederiks et al. 2007) because the natural freezing conditions and true effects of environmental situations that occur in the field cannot be precisely simulated (Paulsen and Heyne 1984; Fuller et al. 2009). On the other hand, field evaluation under natural frost conditions can be a challenge due to the unpredictable nature of frost events, both in timing and severity (Fuller et al. 2007). Within the constraints of natural freezing conditions, the present work indicates that frost temperatures below $-3.9^{\circ} \mathrm{C}$ cause significant damage, and growers would experience more serious yield losses with variety Tahara than other cultivars. Furthermore, triticale was found to be more susceptible than wheat concurring the observation of Rebbeck et al. (2007). However, this finding warrants further confirmation work in the field as growth conditions differ markedly between glasshouse and field.

The current technique of manipulating plants to manage natural frosts holds good potential, and can be considered as one of the alternative screening methods in frost studies. Through this technique, a wide range of plants can be generated and treated to the natural frosts of desired temperatures without exposure to multiple frosts, a major constraint in field based frost studies. With this, the confounding effect of phenology is alleviated. Further, the frost damage symptoms in the current study were identical to those occurring under field conditions confirming the practicability and usefulness of the method. Whereas we confined the treatment of plants in this study, to those within \pm 5 days of anthesis, the same method but different phenological stage, could be similarly tested.

\section{Acknowledgements}

This work was carried out when Sangay Tshewang was on Endeavour Postgraduate Awards Scholarship funded by the Australian Government. Field expenses were supported by the Pork CRC. The authors thank Professor Robert A. Mclntosh, The University of Sydney, Australia for pre-reviewing the manuscript, and are grateful to the two anonymous reviewers for subsequently providing their critical comments. 


\section{References}

Allen, H.M., Pumpa, J.K., Batten, G.D. 2001. Effect of frost on the quality of samples of Janz wheat. Aust. J. Exp. Agric. 41:641-647.

Boer, R., Campbell, L.C., Fletcher, D.J. 1993. Characteristics of frost in a major wheat growing region of Australia. Aust. J. Agric. Res. 44:1731-1743.

Chen, T.H., Gusta, L.V., Fowler, D.B. 1983. Freezing injury and root development in winter cereals. Plant Physiol. 73:773-777.

Cromey, M.G., Wright, D.S.C., Boddington, H.J. 1998. Effects of frost during grain filling on wheat yield and grain structure. N.Z.J. Crop Hortic. Sci. 26:279-290.

Frederiks, T.M., Christopher, J.T., Borrell, A.K. 2008. Low temperature adaption of wheat post head-emergence in northern Australia. In: Proc. of the $11^{\text {th }}$ Int. Wheat Genet. Symp. Brisbane, Australia. pp. 894-896.

Frederiks, T.M., Christopher, J.T., Fletcher, S.E.H., Borrell, A.K. 2011. Post head-emergence frost resistance of barley genotypes in the northern grain region of Australia. Crop Pasture Sci. 62:736-745.

Frederiks, T.M., Christopher, J.T., Harvey, G.L., Sutherland, M.W., Borrell, A.K. 2012. Current and emerging screening methods to identify post head-emergence frost adaptation in wheat and barley. J. Exp. Bot. 63:5405-5416.

Frederiks, T.M., Christopher, J.T., Sutherland, M.W., Borrell, A.K. 2015. Post-head-emergence frost in wheat and barley: defining the problem, assessing the damage, and identifying resistance. J. Exp. Bot. 66:34873498.

Fuller, M.P., Fuller, A.M., Kaniouras, S., Christopher, J.T., Frederiks, T.M. 2007. The freezing characteristics of wheat at ear emergence. Eur. J. Agron. 26:435-441.

Grains Research and Development Corporation. 2013. Frost research targets yield losses. Retrieved from https://grdc.com.au/Media-Centre/Ground-Cover/Ground-Cover-Issue-103-Mar-April-2013/Frostresearch-targets-yield-losses. On 10 June, 2016.

Hacker, J., Ladinig, U., Wagner, J., Neuner, G. 2010. Inflorescences of alpine cushion plants freeze autonomously and may survive subzero temperatures by supercooling. Plant Sci. 180:149-156.

Limin, A.E., Fowler, D.B. 1991. Breeding for cold hardiness in winter wheat: problems, progress and alien gene expression. Field Crops Res. 27:201-218.

Maes, B., Trethowan, R.M., Reynolds, M.P., Ginkel, M., Skovmand, B. 2001. The influence of glume pubescence on spikelet temperature of wheat under freezing conditions. Aust. J. Plant Physiol. 28:141-148.

Marcellos, H., Single, W.V. 1984. Frost injury in wheat ears after ear emergence. Aust. J. Plant Physiol. 11:715.

Paulsen, G.M., Heyne, E.G. 1984. Symptoms of injury to wheat from spring freezes in Kansas. Trans. Kans. Acad. Sci. 87:12-18.

Payton, M.E., Greenstone, M.H., Schenker, N. 2003. Overlapping confidence intervals or standard error intervals: What do they mean in terms of statistical significance? J. of Insect Sci. 3:3-34.

R Development Core Team 2010. R: A Language and Environment for Statistical Computing. R Foundation for Statistical Computing. Vienna, Austria.

Rebbeck, M., Lynch, C., Hayman, P.T., Sadras, V.O. 2007. Delving of sandy surfaced soils reduces frost damage in wheat crops. Aust. J. Agric. Res. 58:105-112.

Reinheimer, J.L., Barr, A.R., Eglinton, J.K. 2004. QTL mapping of chromosomal regions conferreing reproductive frost tolerance in barley (Hordeum vulgare L.). Theor. Appl. Genet. 109:1267-1274.

Roake, J., Trethowan, R., Jessop, R., Fittler, M. 2009. Improved triticale production through breeding and agronomy. A research report. http://www.porkcrc.com.au/1A-102_Final_Research_Report_pdf. Accessed 15 July 2010.

Single, W., Marcellos, H. 1974. Studies on frost injury to wheat. IV. Freezing of ears after emergence from the leaf sheath. Aust. J. Agric. Res. 25:679-686.

Snyder, R.L., Paulo de Melo-Abreu, J. 2005. Frost protection: Fundamentals, Practice, and Economics. Vol. 1. Food and Agriculture Organization of the United Nations. Rome, Italy.

Zheng, B., Chapman, S.C., Christopher, J.T., Frederiks, T.M., Chenu, K. 2015. Frost trends and their estimated impact on yield in the Australian wheatbelt. J. Exp. Bot. 66:3611-3623. 